\title{
BMJ Open Scoping review of potential quality indicators for hip fracture patient care
}

\author{
Kristen B Pitzul, ${ }^{1}$ Sarah E P Munce, ${ }^{2}$ Laure Perrier, ${ }^{3}$ Lauren Beaupre,,${ }^{4,5}$ \\ Suzanne N Morin, ${ }^{6}$ Rhona McGlasson, ${ }^{7}$ Susan $B$ Jaglal ${ }^{1,2,8}$
}

To cite: Pitzul KB,

Munce SEP, Perrier L, et al. Scoping review of potential quality indicators for hip fracture patient care. BMJ Open 2017;7:e014769. doi:10.1136/bmjopen-2016014769

- Prepublication history and additional material is available. To view please visit the journal (http://dx.doi.org/ 10.1136/bmjopen-2016014769).

Received 17 October 2016 Revised 17 January 2017 Accepted 21 February 2017

For numbered affiliations see end of article.

Correspondence to

Kristen B Pitzul;

kristen.pitzul@mail.utoronto.ca

\section{ABSTRACT}

Objective: The purpose of this study is to identify existing or potential quality of care indicators (ie, current indicators as well as process and outcome measures) in the acute or postacute period, or across the continuum of care for older adults with hip fracture.

Design: Scoping review.

Setting: All care settings.

Search strategy: English peer-reviewed studies published from January 2000 to January 2016 were included. Literature search strategies were developed, and the search was peer-reviewed. Two reviewers independently piloted all forms, and all articles were screened in duplicate.

Results: The search yielded 2729 unique articles, of which 302 articles were included (11.1\%). When indicators (eg, in-hospital mortality, acute care length of stay) and potential indicators (eg, comorbidities developed in hospital, walking ability) were grouped by the outcome or process construct they were trying to measure, the most common constructs were measures of mortality (outcome), length of stay (process) and time-sensitive measures (process). There was heterogeneity in definitions within constructs between studies. There was also a paucity of indicators and potential indicators in the postacute period.

Conclusions: To improve quality of care for patients with hip fracture and create a more efficient healthcare system, mechanisms for the measurement of quality of care across the entire continuum, not just during the acute period, are required. Future research should focus on decreasing the heterogeneity in definitions of quality indicators and the development and implementation of quality indicators for the postacute period.

\section{BACKGROUND}

In $2000, \sim 1.6$ million people worldwide suffered from a fragility hip fracture (herein referred to as 'hip fracture'), with this number projected to increase to 21 million by the year $2050 .^{12}$ In the UK alone, there is predicted to be over 100000 hip fractures by the year 2020. ${ }^{3}$ Half of the persons who suffer from hip fractures never return to

\section{Strengths and limitations of this study}

This study includes potential indicators and indicators for hip fracture quality of care throughout the entire continuum of care and not just within the acute care period.

- The search strategy was performed by an experienced information scientist and peer-reviewed by another information scientist outside the study team.

- The screening and extraction were performed completely in duplicate.

- Non-English studies were not included, and there may therefore be a bias towards inclusion of studies performed in English-speaking countries.

premorbid function, even two years postfracture, and the direct attributable one-year mortality rates for hip fractures are between 20 and $30 \%{ }^{4-7}$ Patients with hip fractures have significantly higher acute care costs than matched controls as well as high postacute costs due to rehabilitation required after surgery. $^{7-12}$

To help mitigate this extensive morbidity, mortality and healthcare use, it is imperative that quality care is delivered to patients with hip fracture. The Institute of Medicine defines quality care as "the degree to which health services for individuals and populations increase the likelihood of desired health outcomes and are consistent with current professional knowledge". ${ }^{13}$ In essence, delivering quality care means delivering evidence-based care that has a good chance of improving a patient's health outcome(s).

To ensure that quality care is delivered, a number of countries that have traditionally funded their institutions with global budgets (eg, Canada, ${ }^{14}$ the $\mathrm{UK}^{15}$ ) have begun implementing performance-based funding (ie, linking quality of care delivery to funding policies). One of the goals of performancebased funding, such as the Best Practice Tariff implemented in 2010 in the UK, is to assign increased accountability to institutions for the care that they deliver. ${ }^{16}$ Although the 
measurement of quality of care has always been imperative to healthcare delivery, the importance of choosing which aspects of quality of care to measure is highlighted in the context of performance-based funding models. $^{17}$

Quality of care indicators are typically embedded within a performance framework (eg, a balanced scorecard) and are used to measure the structure, process and/or outcomes of care ${ }^{18-20}$ Quality of care indicators measure how much deviation (if any) there is between the healthcare being delivered and best practice. $^{13}$ Examples of the use of quality of care indicators to improve care delivery include the Surgical Safety Checklist (implemented in eight countries), and the National Hip Fracture Audit in the UK. ${ }^{15}{ }^{21}$ There are a variety of approaches for developing quality of care indicators, including deductive (from concept to data) and inductive (from data to concept). ${ }^{17} 22{ }^{23}$ Using either approach, when evidence is weak or non-existent, expert consensus is used to develop the indicator. ${ }^{23}$

Current hip fracture quality of care indicators target the acute care period, most likely due to the focus on performance-based funding for acute care institutions (ie, an incentive to measure quality). In the UK, The National Institute for Health and Care Excellence (NICE), along with the British Orthopaedics Association (BOA), has developed several hip fracture quality indicators (eg, time to surgery, assessment by ortho-geriatrician within 72 hours of admission) as part of their performance-based funding for acute care. ${ }^{3} \quad \begin{array}{lll}15 & 24 & 25\end{array}$ These indicators have subsequently been used in other health systems worldwide (eg, Australia, Canada and other European countries) ${ }^{26-33}$ However, these indicators are focused solely in the acute care period and therefore do not measure the quality of care in the postacute care period.

Although some studies have used process and outcome measures to evaluate care delivered in the postacute period (eg, a home-based rehabilitation programme), there is a lack of identified, evidence-based quality of care indicators in the postacute care period for patients with hip fracture. ${ }^{34-38}$ Without measures of quality of care in the postacute period for patients with hip fracture, frontline staff, administrators and policymakers are left without required information to assess the delivery of care during the postsurgical rehabilitation period. ${ }^{39} 40$

The objective of this study is to synthesise the evidence on existing or potential quality of care indicators for the acute period, the postacute period and across the entire continuum of care for patients following a hip fracture. Using a scoping review methodology, the specific research question to be addressed was: "What patient, institutional, and system-level indicators are currently in use or could potentially be used for measuring quality of care in the acute period, post-acute period, and across the continuum for older individuals following a hip fracture?".
METHODS

\section{Study design and literature search strategies}

A scoping review methodology was employed, of which details are published elsewhere (see online supplementary file 1). ${ }^{41}$ Briefly, Arksey and O'Malley ${ }^{42}$ as well as Levac $e t a t^{43}$ frameworks were used to guide the scoping review. Measures targeted at patients, institutions or health systems were included and encompassed care processes and outcomes in the acute and postacute period. For the purposes of this review, quality indicators were defined as validated process or outcome measures with a descriptive statement that were used to describe quality of care delivered. ${ }^{22}$ A potential quality indicator was defined as a process or outcome measure of care that was not specifically identified or referenced as an indicator of quality of care by the authors. This synthesis focused on quality of care indicators for older adults (aged 50 years and over) with non-pathological hip fracture caused by low trauma (eg, a fall from standing height or less). All study designs were included and only studies or abstracts published from the year 2000-January 2016, or in English were included to ensure relevance to the current healthcare context and feasibility.

Literature search strategies were developed using medical subject headings (MeSH) and text words related to hip fracture quality indicators. MEDLINE, EMBASE, CINAHL, Ageline, PEDRO (physiotherapy evidence database) and the Cochrane Central Register of Controlled Trials (CENTRAL) databases were searched on 18 January 2016, and the MEDLINE search was peerreviewed. ${ }^{44}$ Searches were performed with no language restrictions and limited from 1 January 2000 (see online supplementary file 2). The search used combinations of the following terms: hip fracture, femoral fracture, process indicator, process measure and quality indicator. Appropriate wildcards were used in the search to account for plurals and variations in spelling.

\section{Study selection and data abstraction}

Two reviewers (KBP and SEPM) piloted level 1 (titles and abstracts) and level 2 (full article texts) screening forms, as well as the extraction form (see online supplementary file 3). All screening and extraction were completed in duplicate. Disagreements were discussed between the two reviewers and a third party reviewer (LB, SNM or SBJ) was contacted if disagreements could not be resolved.

Abstracted data included study characteristics (eg, year of publication, country of study), indicator definitions (eg, length of stay defined as the number of total days stayed at institution without interruption) and numerator and denominator definitions when applicable (eg, per 1000 hip fractures). We examined the purpose and components of the indicators as well as the reported measurement properties, if applicable. Study setting was abstracted and defined as follows: acute care (any acute care institution or department within an acute care 
institution); postacute care (any institution or community setting used after discharge from acute care) or across the continuum of care (studies that include acute and postacute settings). Study quality was not assessed during the scoping review as the objective of a scoping review is to identify gaps in the literature and highlight future areas for systematic review. ${ }^{42}{ }^{43}$ Studies were then summarised using numerical counts, and definitions of indicators or potential indicators were summarised.

\section{RESULTS}

The literature searches yielded a total of 3828 articles (figure 1). After duplicates were removed, 2729 articles were included in level 1 screening. After level 1 screening was complete, 638 articles $(23 \%)$ were included in full-text screening (ie, level 2). After level 2 screening was complete, data were extracted from 302 articles (11\% of initial yield). Agreement between the two reviewers (KBP and SEPM) ranged from 75 to $85 \%$ for both searches. Reasons for article exclusion varied, but were primarily due to incorrect study population (ie, study included older adults with pathological hip fractures).

\section{Synthesis}

Owing to the volume of studies included in data extraction $(\mathrm{N}=302)$, indicators or potential indicators were grouped into process and outcome constructs that the authors were trying to measure. The creation of these constructs was therefore data-driven and included measures of mortality, time-to (eg, time to surgery, time spent in the emergency department), length of stay, functional ability, comorbidities and complications, discharge destinations, balance and mobility, quality of life, pain, cognitive, readmissions, the UK's Best Practice Tariff indicators (BPTs), prophylaxis (eg, antibiotic prophylaxis) and blood (eg, blood loss, blood transfusion), osteoporosis testing and medications, falls, healthcare usage, nutrition (eg, vitamin D levels), biometrics (eg, muscle strength tests), catheters, patient satisfaction, caregivers (eg, burden and stress), self-efficacy (eg, self-
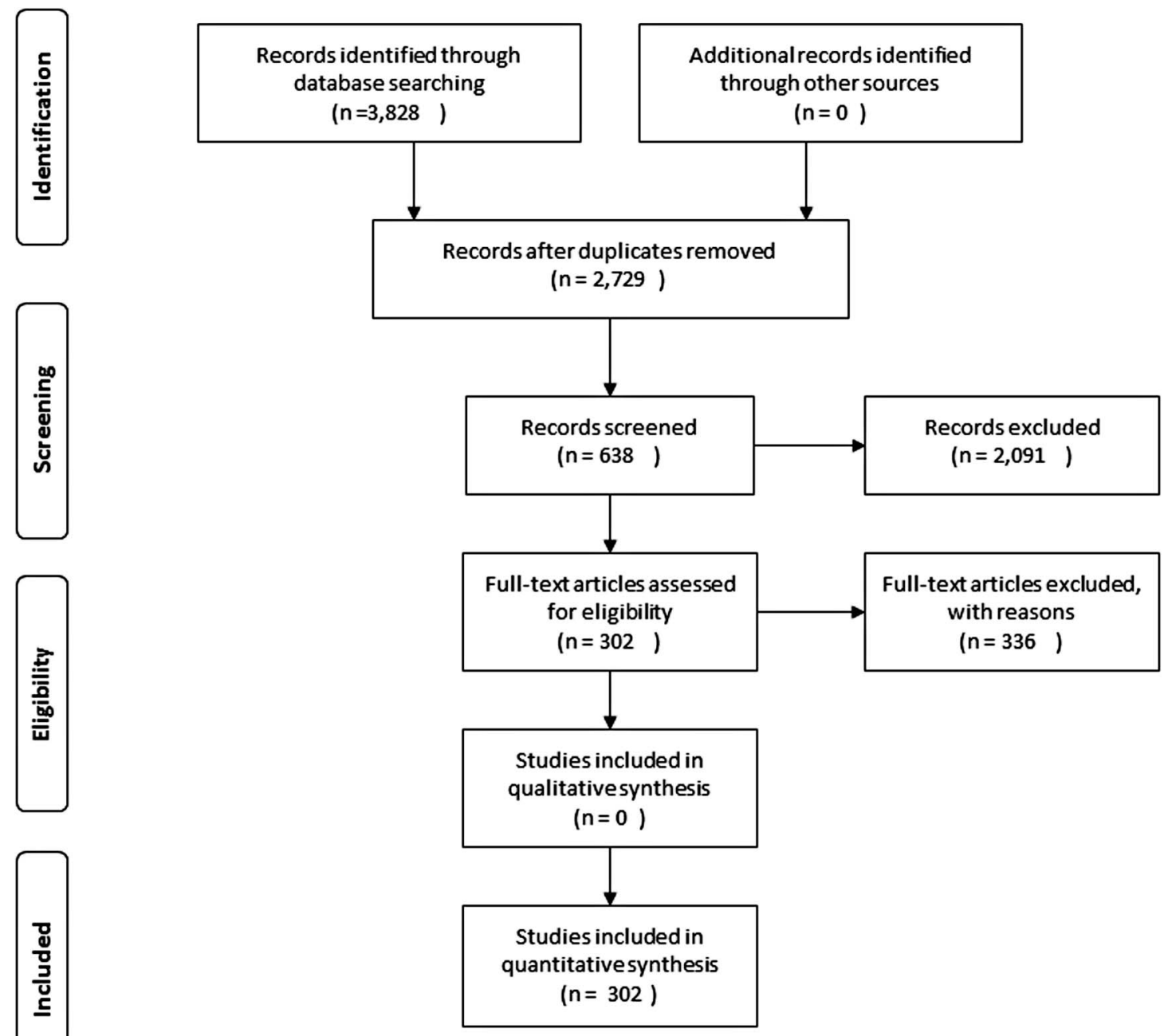

Figure 1 The total number of articles yielded from the literature search in 2016, and the final number of articles included in the study. CENTRAL, the Cochrane Central Register of Controlled Trials; PEDRO, physiotherapy evidence database. 
care ability) and other (eg, patient safety strategies). Developing these constructs greatly improved the feasibility of data synthesis, particularly for comparing variations in indicator or potential indicator definitions between studies. If the same indicator or potential indicator (eg, Berg Balance Scale) was used by different studies for measuring different constructs (eg, functional ability as well as balance and mobility), it was placed into all relevant constructs. Owing to the nature of the topic reviewed (ie, indicators or potential indicators), after screening, there were no qualitative studies for data extraction.

\section{General characteristics of included studies}

When individual countries were compared, most studies were conducted in the UK $(27 \%)$, the USA $(22 \%)$ or Australia and New Zealand (13\%) (table 1). Most study settings were within the acute care period $(78 \%)$, with a paucity of studies conducted in the postacute care period $(8 \%)$ (table 1). The most common study design was retrospective cohort $(28 \%)$, followed by prospective cohort $(18 \%)$ and reviews $(17 \%)$ (table 1). Within the included studies, the majority of indicators or potential indicators were at the patient level.

Table 1 Country of study, study setting and study design, number of included studies ( $\mathrm{n}, \%$ total $n$ )

\begin{tabular}{lc}
\hline & $\begin{array}{c}\text { Number (\% total }{ }^{\star} \text { ) } \\
\text { of Studies }\end{array}$ \\
\hline Country of study & \\
Other Europe & $84(28 \%)$ \\
UK & $81(27 \%)$ \\
USA & $67(22 \%)$ \\
Australia and New Zealand & $39(13 \%)$ \\
Nordic Countries (Norway, & $48(16 \%)$ \\
Denmark, Finland, Sweden) & \\
Canada & $28(9 \%)$ \\
Asia & $13(4 \%)$ \\
Middle East (Israel, India) & $8(3 \%)$ \\
Study setting & \\
Acute & $237(78 \%)$ \\
Postacute (any) & $24(8 \%)$ \\
Across the continuum of care & $41(14 \%)$ \\
Study design & \\
Retrospective cohort & $85(28 \%)$ \\
Prospective cohort & $53(18 \%)$ \\
Review (scoping, systematic, etc) & $50(17 \%)$ \\
Randomised controlled trial & $34(11 \%)$ \\
Clinical Audit & $31(10 \%)$ \\
Experimental (eg, pre-post) & $19(6 \%)$ \\
Population-based cohort & $9(3 \%)$ \\
Descriptive & $7(2 \%)$ \\
Cross-sectional & $6(2 \%)$ \\
Focus groups/interviews/ & $4(1 \%)$ \\
consensus meetings & $2(1 \%)$ \\
Pilot study & $2(1 \%)$ \\
Survey & \\
\hline
\end{tabular}

${ }^{\star}$ The total percentage does not add up to $100 \%$ for country of study as some studies took place in multiple countries.
Most common indicators or potential indicators

When indicators or potential indicators were grouped into process and outcome constructs, mortality and time-to (eg, time to surgery) constructs were most commonly reported $(42 \%$ and $35 \%$, respectively, of the included studies) (table 2). Length of stay, functional ability, comorbidities and complications, discharge destinations and balance and mobility indicators or potential indicators were present in over $20 \%$ of the included studies. Indicators or potential indicators of self-efficacy, caregivers and patient satisfaction were the least commonly reported (2\%, $2 \%$ and $2 \%$, respectively).

\section{Indicators or potential indicators by study setting}

When the constructs are stratified by study setting, the paucity of potential indicators or indicators in the postacute period or across the continuum of care is highlighted (table 3). All of the studies with indicators or potential indicators in the Best Practice Tariff construct are set in the acute care period, as are the vast majority of studies with indicators or potential indicators in the 'other' construct $(88 \%)$ or within the 'time-to' construct $(87 \%)$ (table 3$)$.

The proportion of studies with indicators or potential indicators classified as functional ability or quality of life constructs was distributed between the acute care and the postacute periods as well as across the continuum of care (table 3). Since the goal of rehabilitation is to restore prefracture functional ability and quality of life, this broader distribution is not surprising. Finally, certain indicators or potential indicators are unlikely to occur in the postacute period because they are less relevant (eg, those within the catheter or prophylaxis and blood constructs) (table 3).

When indicators or potential indicators were examined within each construct, there was substantial heterogeneity in definitions, including variations in when the indicator or potential indicator was measured, as well as the categorisation of categorical measures (eg, different cutpoints on a scale). For example, length of acute care stay was measured from time to ward admission to discharge as well as from time to emergency department presentation to discharge ${ }^{45}{ }^{46}$ Definitions of time to surgery also varied, as some studies defined time to surgery as the time from medical stability to surgery; ${ }^{47} 48$ some studies defined time to surgery as time from admission to surgery, ${ }^{48-55}$ and others created a binary variable for time to surgery (eg, had surgery within 24 hours).$^{56-59}$ The one exception was the UK's Best Practice Tariff indicators, which are clearly defined across studies.

Compared to potential indicators or indicators implemented in the acute care period, even greater variability was seen for potential indicators or indicators implemented in the postacute period. Potential indicators and indicators within the functional ability and quality of life constructs are discussed below as exemplifiers of this extensive variability, as both constructs are established goals of rehabilitation and were prevalent in studies set in the postacute period and/or across the continuum of care (see online supplementary files 4 and 5). 
Table 2 Number of studies ( $\mathrm{n}, \%$ total $\mathrm{N}$ studies), by process or outcome constructs containing indicators or potential indicators

\begin{tabular}{|c|c|c|}
\hline Construct & Indicators or potential indicators & n (\%N) \\
\hline Mortality & In-hospital mortality; postdischarge mortality (eg, 30 days, 90 days) & $125(41 \%)$ \\
\hline Time-to & $\begin{array}{l}\text { Time from presentation to admission; time from admission to medical } \\
\text { clearance; time from admission to surgery/surgical delay; operative time; time to } \\
\text { rehabilitation }\end{array}$ & $106(35 \%)$ \\
\hline Length of stay & $\begin{array}{l}\text { During acute care; during intensive care; during rehabilitation; during a } \\
\text { readmission }\end{array}$ & $93(31 \%)$ \\
\hline $\begin{array}{l}\text { Comorbidities and } \\
\text { complications }\end{array}$ & $\begin{array}{l}\text { Developed in-hospital; developed postoperatively; number present at } \\
\text { admission; classification (major vs minor); adverse events in-hospital; pressure } \\
\text { ulcers; urinary tract infections; venous thromboembolism; reoperation; infections }\end{array}$ & $86(29 \%)$ \\
\hline Functional ability & $\begin{array}{l}\text { Activities of daily living (ADLs) or instrumental ADLs (IADLs); short physical } \\
\text { performance battery (SPPB); functional independence measure (FIM); Barthel } \\
\text { or Modified Barthel Index; Katz or Modified Katz; Timed up and go; Harris Hip } \\
\text { Score; SF36; Tinetti's Fall Efficacy Scale; Berg Balance Scale; sit to stand test; } \\
\text { Frenchay's Activity Index; Activity Measure for Post-acute care (AM-PAC); } \\
\text { Other measures }\end{array}$ & $84(28 \%)$ \\
\hline Discharge destinations & $\begin{array}{l}\text { Novel institutionalisation; change in premorbid level of care; discharge } \\
\text { destination (eg, home, long-term care); successful community discharge }\end{array}$ & $64(21 \%)$ \\
\hline Balance and mobility & $\begin{array}{l}\text { Mobile yes/no; ability (eg, walking distance); ambulation decline; balance (eg, } \\
\text { postural sway); weight bearing }\end{array}$ & $62(21 \%)$ \\
\hline Quality of life (QOL) & $\begin{array}{l}\text { EQ5D, EuroQOL (includes EQ5D and EQ-Visual Analog Scale); Health-related } \\
\text { QOL (HRQOL); Dementia assessment for QOL (DEMQOL); Swedish QOL } \\
\text { (SWED-QUAL); WHO's Brief QOL (WHOQOL-BREF); Short Form } 12 \text { (SF12), } \\
36 \text { (SF36) and 6D (SF6D); Western Ontario and McMaster Short Form } \\
\text { (WOMAC-SF); Other (eg, Health Utilities Index) }\end{array}$ & $39(13.0 \%)$ \\
\hline Other & $\begin{array}{l}\text { Organisation's performance evaluation system ( } 130 \text { simple indicators and } 50 \\
\text { composite measures); day of admission; maintainability (ie, unexpected event, } \\
\text { including deaths, readmission or change in level of care); weight; composite } \\
\text { poor outcome (eg, death or readmission); patient safety strategies }\end{array}$ & $30(10 \%)$ \\
\hline Pain & $\begin{array}{l}\text { Presence of pain (acute, chronic); pain score in EQ5D; assessment of pain } \\
\text { (yes/no); use of analgesia (yes/no and type) }\end{array}$ & $29(10 \%)$ \\
\hline Readmissions & 15,28 or 30 days; 2 months, 4 months, monthly; 1 year & $26(9 \%)$ \\
\hline Cognitive & $\begin{array}{l}\text { Score or status (eg, mini mental status examination score); depression (yes/ } \\
\text { no); delirium (yes/no) }\end{array}$ & $25(8 \%)$ \\
\hline $\begin{array}{l}\text { UK's Best Practice Tariff } \\
\text { Indicators (BPT) }\end{array}$ & $\begin{array}{l}\text { Admission under consultant-led joint orthogeriatric care; admission using a } \\
\text { multidisciplinary assessment protocol; Geriatric-directed multidisciplinary } \\
\text { rehabilitation; perioperative assessment by geriatrician or ortho-geriatrician } \\
\text { within } 72 \text { hours of admission to emergency department; Admission to ward from } \\
\text { emergency department within } 4 \text { hours; Assessment for falls and bone } \\
\text { protection }\end{array}$ & $24(8 \%)$ \\
\hline Prophylaxis and blood & $\begin{array}{l}\text { Antibiotic prophylaxis and anticoagulation (yes/no and type); blood loss } \\
\text { (amount); blood transfusion (yes/no) }\end{array}$ & $23(8 \%)$ \\
\hline $\begin{array}{l}\text { Osteoporosis testing and } \\
\text { medication }\end{array}$ & Bone mineral density testing; medication postoperatively or at acute discharge & $21(7 \%)$ \\
\hline Falls & $\begin{array}{l}\text { Crude count; prevention (eg, falls prevention programme); assessment for falls } \\
\text { risk (in-hospital and postdischarge); Tinetti's fall efficacy scale; self-report falls } \\
\text { at various time points postacute discharge }\end{array}$ & $19(6 \%)$ \\
\hline Healthcare usage & $\begin{array}{l}\text { Costs; community services; physical therapy visits (acute and postacute); } \\
\text { composite measures (readmission, emergency department visit) }\end{array}$ & $16(5 \%)$ \\
\hline Nutrition & $\begin{array}{l}\text { Compliance with diet/nutrition interventions; vitamin D (amount); assessment } \\
\text { (includes time to assessment) }\end{array}$ & $13(4 \%)$ \\
\hline Biometrics & $\begin{array}{l}\text { Neuromuscular assessment or status; muscle strength; muscle contraction; } \\
\text { knee specific measures }\end{array}$ & $11(4 \%)$ \\
\hline Catheters & Catheter yes/no; time to removal & $8(3 \%)$ \\
\hline Patient satisfaction & $\begin{array}{l}\text { Questionnaire/interview with various questions (eg, questions about satisfaction } \\
\text { with information provided about hospital care) }\end{array}$ & $5(2 \%)$ \\
\hline Caregivers & $\begin{array}{l}\text { Support provided (eg, Social Support Scale); burden and stress (eg, Caregiver } \\
\text { Strain Index) }\end{array}$ & $4(1 \%)$ \\
\hline Self-efficacy & Self-care ability; self-efficacy for exercise & $4(1 \%)$ \\
\hline
\end{tabular}


Table 3 Construct of indicators or potential indicators, stratified by study setting ( $\mathrm{n}$ and $\%$ total $\mathrm{N}$ of each construct)

\begin{tabular}{|c|c|c|c|}
\hline Construct & Acute $(n, \% N)$ & Postacute (n, \% N) & Across the continuum $(n, \% N)$ \\
\hline Mortality & $95(76 \%)$ & $6(5 \%)$ & $24(19 \%)$ \\
\hline Time-to & $93(88 \%)$ & $0(0 \%)$ & $13(12 \%)$ \\
\hline Length of stay & $65(70 \%)$ & $8(9 \%)$ & $20(22 \%)$ \\
\hline Comorbidities and complications & $60(69 \%)$ & $2(2 \%)$ & $24(28 \%)$ \\
\hline Functional ability & $51(50 \%)$ & $22(26 \%)$ & $25(30 \%)$ \\
\hline Discharge destination & $38(59 \%)$ & $13(20 \%)$ & $13(20 \%)$ \\
\hline Balance and mobility & $33(53 \%)$ & $12(19 \%)$ & $17(27 \%)$ \\
\hline Quality of life & 15 (39\%) & 9 (22\%) & 15 (37\%) \\
\hline Other & $26(87 \%)$ & $0(0 \%)$ & $4(13 \%)$ \\
\hline Pain & $17(59 \%)$ & $4(14 \%)$ & $8(28 \%)$ \\
\hline Readmissions & $15(58 \%)$ & $3(12 \%)$ & $8(31 \%)$ \\
\hline Cognitive & $17(68 \%)$ & $4(16 \%)$ & $4(16 \%)$ \\
\hline Best practice tariff & $24(100 \%)$ & $0(0 \%)$ & $0(0 \%)$ \\
\hline Prophylaxis and blood & $17(74 \%)$ & $0(0 \%)$ & $6(26 \%)$ \\
\hline Osteoporosis testing and medication & $16(76 \%)$ & $2(10 \%)$ & $3(14 \%)$ \\
\hline Falls & $14(74 \%)$ & $3(16 \%)$ & $2(11 \%)$ \\
\hline Healthcare utilization & $8(50 \%)$ & $5(31 \%)$ & $3(19 \%)$ \\
\hline Nutrition & $10(77 \%)$ & $0(0 \%)$ & $3(23 \%)$ \\
\hline Biometrics & $2(18 \%)$ & $9(82 \%)$ & $0(0 \%)$ \\
\hline Catheters & $6(69 \%)$ & $0(0 \%)$ & $2(25 \%)$ \\
\hline Patient satisfaction & $2(40 \%)$ & $0(0 \%)$ & $3(60 \%)$ \\
\hline Caregivers & $1(25 \%)$ & $1(25 \%)$ & $2(50 \%)$ \\
\hline Self-efficacy & $2(50 \%)$ & $2(50 \%)$ & $0(0 \%)$ \\
\hline
\end{tabular}

Indicators or potential indicators in postacute: functional ability and quality of life

Most measures of functional ability were validated scores or scales, such as the Functional Independence Measure (FIM) ${ }^{60-72}$ the Barthel Index (BI) (or Modified Barthel Index (MBI) $){ }^{38}{ }^{73-91}$ and the Activity Measure for Post-acute Care (AM-PAC) ${ }^{34} 92$ (see online supplementary file 4). Furthermore, change in functional ability (ie, difference in functional ability between two time points) ${ }^{36} 69707893-97$ was only used in $13.0 \%$ of studies measuring functional ability (see online supplementary file 4).

Quality of life, similar to functional ability, was measured primarily using validated scores or scales, such as the SF36 $3866768797-102$ (see online supplementary file $5)$. Some studies used modified validated scales or scores, such as the EuroQOL (European Quality of Life measure which includes EQ5D and a visual analogue scale for pain). ${ }^{103}{ }^{104}$ When quality of life was measured, it varied substantially from 3 to 4 days postoperatively to 1 year after acute care discharge. ${ }^{76} 102105$ Changes in quality of life between two time points (compared to measurement of quality of life at one time point) were not measured in any of the included studies (see online supplementary file 5).

\section{DISCUSSION}

The purpose of this study was to synthesise the literature for quality indicators or potential quality indicators for patients with hip fracture within the acute period, postacute period and across the continuum of care. Most studies were from the UK and contained patientlevel indicators implemented within the acute care period. There was substantial variability in terms of indicator or potential indicator definitions among studies, particularly in the postacute period. This is particularly evident in the functional ability and quality of life constructs, two outcome constructs that are important to rehabilitation of patients with hip fracture.

The most common process or outcome constructs were those that measured mortality, 'time-to' (eg, time spent in the emergency department on presentation) and length of stay. They were most often implemented in the acute care period. This prevalence may be, in part, due to the fact that these constructs contain measures currently in use as quality indicators in numerous health systems: in-hospital and 30-day mortality, time from emergency department to acute admission and time to surgery. ${ }^{3} 14{ }^{24}$ However, even with respect to these known metrics, there were differences in time and type of measurement between studies. Although these differences may sometimes appear to be nuanced or negligible (eg, whether or not length of acute care stay includes time spent in the emergency department), they can be impactful if the indicator or potential indicators play a role in institutional funding (ie, performancebased funding). Differences in definitions may also be due to changes in best practice that occurred during the study time frame (eg, recommendation of time to surgery within 48 hours compared to time to surgery within 36 hours). ${ }^{3} 24$ 
This study highlights the lack of indicators or potential indicators implemented within the postacute care period for patients with hip fracture in the literature. This finding supports the conclusions of Duncan and Velozo $^{39}$ and Leland and colleagues. ${ }^{40}$ Almost 10 years ago, Duncan and Velozo concluded that although validated outcome measures exist in the postacute rehabilitation period, there is a lack of quality indicators to actually assess the care delivered in the USA. ${ }^{39}$ Similar conclusions were made more recently by Leland and colleagues, who stated that owing to the limited number of quality of care measures in the postacute period, stakeholders (ie, patients, families, payers and providers) are left without required information to make important decisions for hip fracture rehabilitation in the USA. ${ }^{106}$ Two important potential indictors for quality of rehabilitative care in the postacute period that were found in the literature were functional ability and quality of life.

Functional ability and quality of life constructs were very heterogeneous, in terms of potential indicators and indicator definitions, with no dominant measure reported, making comparisons among studies difficult. This also limits the utility of evidence in the development of quality indicators that can be applied to entire health systems and tied to financial models. The heterogeneity between performance measures for hip fracture was also discussed in a review performed by Giusti and colleagues, which concluded that measures for functional ability varied so substantially that results between studies were not comparable. ${ }^{107}$

The results of this study are supported by current literature in other rehabilitation populations. Mont et $a l^{108}$ found that few rating scales assessed all aspects of outcomes (including quality of life, rehabilitative and patient satisfaction) following total knee arthroplasty. A systematic review by Ritchie $e t a l^{109}$ on measures of community integration for persons with traumatic brain injury found that more research is needed to inform best practice guidelines. Sleat et $a l^{10}$ reviewed current practice of trauma registries and found that most registries failed to measure outcomes such as morbidity and quality of life, which are needed to drive service improvement in the long term. Rinere O'Brien systematically reviewed the evidence to determine the impact of a new payment system implemented in the USA on quality of care indicators for inpatient stroke rehabilitation and found that lack of data with respect to the quality of care indicators made it difficult to ascertain conclusions. ${ }^{111}$

Recently, however, cardiac rehabilitation (which includes stroke rehabilitation) has made progress in terms of quality indicator development and implementation compared to other rehabilitation populations. ${ }^{112}$ Grace $e t a l^{12}$ described the creation of quality indicators for cardiac rehabilitation (eg, 'percentage of eligible in-patients referred to a cardiac rehabilitation program' and 'number of days between receipt of referral to a cardiac rehabilitation program and patient enrollment for eligible patients') and secondary prevention through a literature review and consensus process led by the Canadian Cardiovascular Society. These advancements in quality indicators for cardiac rehabilitation can help inform future research and protocols on the development of indicators to assess quality of care delivered to patients with hip fracture and other rehabilitation populations in the postacute period.

This study was not without limitations. First, scoping reviews do not assess study quality and, as such, information extracted from weak and strong studies is considered. Second, non-English studies were not included and there may therefore be a bias towards inclusion of studies performed in English-speaking countries. Third, owing to the considerable amount of time required to conduct scoping reviews, the search was completed 11 months ago and therefore more recent and relevant studies may be excluded. Fourth, inclusion of original research and review articles may have resulted in duplication of some results.

Despite these limitations, this study has several strengths. First, it includes potential indicators and indicators for hip fracture quality of care throughout the entire continuum of care and not just within the acute care period. Second, the literature search was performed by an experienced information scientist, and the screening and extraction were performed completely in duplicate. Third, the search itself was peer-reviewed.

To improve quality of care for patients and create a more efficient healthcare system, mechanisms for the measurement of quality of care are required. The implementation of quality of care indicators enables stakeholders to target areas for improvement in service delivery. Although acute care quality indicators for patients with hip fracture have been implemented in many health systems, there is a paucity of indicators and heterogeneity in potential indicators in the postacute care period. Owing to the requirement for rehabilitation after surgery for patients with hip fracture, the inability to measure quality of care in the postacute period is concerning. Future research should focus on collaborative efforts to decrease indicator heterogeneity as well as to develop a framework for indicators that could be shared globally. This would increase accountability and help ensure that quality care is delivered to patients with hip fracture worldwide.

\section{Author affiliations}

${ }^{1}$ Institute of Health Policy, Management, and Evaluation, University of

Toronto, Toronto, Ontario, Canada

${ }^{2}$ Toronto Rehabilitation Institute, University Health Network, Toronto, Ontario, Canada

${ }^{3}$ Gerstein Science Information Centre, University of Toronto, Toronto, Ontario, Canada

${ }^{4}$ Department of Physical Therapy, University of Alberta, Edmonton, Alberta, Canada

${ }^{5}$ Department of Surgery, University of Alberta, Edmonton, Alberta, Canada

${ }^{6}$ Department of Medicine, McGill University, Montreal, Quebec, Canada

${ }^{7}$ Bone and Joint Canada, Toronto, Ontario, Canada

${ }^{8}$ Department of Physical Therapy, University of Toronto, Toronto, Ontario, Canada 
Acknowledgements The authors thank Ms Saima Hossain, Ms Atiya Hemraj and Ms Julie Zhang for their help in retrieving articles.

Contributors KBP involved in writing protocol, screening for all levels, extraction, synthesis and writing of manuscripts and was the project coordinator. SEPM involved in editing of protocol, screening for all levels, extraction, synthesis and editing manuscripts. LP involved in editing of protocol, search strategy and editing manuscripts. LB contributed to editing of protocol, content expert input (rehabilitation), partial screening level 1 and editing manuscripts. SNM involved in editing of protocol, content expert input (clinical), partial screening level 1 and editing manuscripts. RM contributed to editing of protocol, stakeholder input (BJC), partial screening level 1 and editing manuscripts. SBJ involved in project conception, editing of protocol, partial screening level 1 and editing manuscripts and was the senior responsible investigator

Funding This work was supported by a Technology Evaluation in the Elderly Network Knowledge Synthesis Grant \# 2013-07, which is funded federally through the National Centers of Excellence.

Competing interests None declared.

Provenance and peer review Not commissioned; externally peer reviewed.

Data sharing statement Further details on studies included in this scoping review can be retrieved by contacting the corresponding author at kristen. pitzul@mail.utoronto.ca.

Open Access This is an Open Access article distributed in accordance with the Creative Commons Attribution Non Commercial (CC BY-NC 4.0) license, which permits others to distribute, remix, adapt, build upon this work noncommercially, and license their derivative works on different terms, provided the original work is properly cited and the use is non-commercial. See: http:// creativecommons.org/licenses/by-nc/4.0/

\section{REFERENCES}

1. Parker M, Johansen A. Hip Fracture. BMJ 2006;333:27-30.

2. Johnell O, Kanis JA. An estimate of the worldwide prevalence and disability associated with osteoporotic fractures. Osteoporos Int 2006;17:1726-33

3. British-Orthopaedic-Association. The care of patients with fragility fractures. British Orthopaedic Association, 2007. http://www.bgs. org.uk/pdf_cms/pubs/Blue\%20Book\%20on\%20fragility\%20fracture \%20care.pdf.

4. Bertram M, Norman R, Kemp L, et al. Review of the long-term disability associated with hip fractures. Inj Prev 2011;17:365-70.

5. Magaziner J, Fredman L, Hawkes W, et al. Changes in functional status attributable to hip fracture: a comparison of hip fracture patients to community-dwelling aged. Am J Epidemiol 2003;157:1023-31.

6. Norton R, Butler M, Robinson E, et al. Declines in physical functioning attributable to hip fracture among older people: a follow-up study of case-control participants. Disabil Rehabil 2000;22:345-51.

7. Nikitovic M, Wodchis WP, Krahn MD, et al. Direct health-care costs attributed to hip fractures among seniors: a matched cohort study. Osteoporos Int 2013;24:659-69.

8. Stukel TA, Fisher ES, Alter DA, et al. Association of hospital spending intensity with mortality and readmission rates in Ontario hospitals. J Am Med Assoc 2012;10:1037-45.

9. Wilkins K. Health care consequences of falls for seniors. Health Rep 1999;10:47-55.

10. Haentjens $\mathrm{P}$, Autier $\mathrm{P}$, Barette $\mathrm{M}$, et al. The economic cost of hip fractures among elderly women. A one-year, prospective, observational cohort study with matched-pair analysis. Belgian Hip Fracture Study Group. J Bone Joint Surg Am 2001;4:493-500.

11. Dai K, Zhang W, Fan $\mathrm{T}$, et al. Estimation of resource utilization associated with osteoporotic hip fracture and level of post-acute care in China. Curr Med Res Opinion 2007;23:2937-43.

12. Pasco JA, Sanders KM, Hoekstra FM, et al. The human cost of fracture. Osteoporos Int 2005;16:2046-52.

13. IOM. Crossing the Quality Chasm: A new health system for the 21st century. Washington (DC): Institute of Medicine, 2001.

14. HQO, MOHLTC. Quality-based procedures: clinical handbook for hip fracture. Toronto (ON): Health Quality Ontario, 2013

15. Royal-College-of-Physicians. National Hip Fracture Database (NHFD) annual report 2014. London: Royal-College-of-Physicians, 2014.
16. Department-of-Health. Prevention package for older people. http:// webarchive.nationalarchives.gov.uk/20130107105354/http://dh.gov. uk/en/index.htm. 2009.

17. Shekelle PG. Quality indicators and performance measures: methods for development need more standardization. J Clin Epidemiol 2013;66:1338-9.

18. Donabedian A. The quality of care: how can it be assessed? J Am Med Assoc 1988;260:1743-8.

19. Arah OA, Klazinga NS, Delnoij DMJ, et al. Conceptual frameworks for health systems performance: a quest for effectiveness, quality, and improvement. Int J Qual Health Care 2003;15:377-98.

20. Kaplan RS, Norton DP. The balanced scorecard-measures that drive performance. Harv Bus Rev 1992;70:71-9.

21. Haynes AB, Weiser TG, Berry WR, et al. A surgical safety checklist to reduce morbidity and mortality in a global population. $N$ Engl J Med 2009;360:491-9.

22. Stelfox HT, Bobranska-Artiuch B, Nathens A, et al. Quality indicators for evaluating trauma care: a scoping review. Arch Surg 2010;145:286-95.

23. Stelfox HT, Straus SE. Measuring quality of care: considering conceptual approaches to quality indicator development and evaluation. J Clin Epidemiol 2013;66:1328-37.

24. NICE publishes advice on management of hip fracture. Guidelines in Practice 2011;14:8.

25. NHS. NHS performance indicators: a consultation. London: NHS, 2001.

26. Sivakumar BS, McDermott LM, Bell JJ. Dedicated hip fracture service: implementing a novel model of care. ANZ J Surg 2013;83:559-63.

27. Khan SK, Weusten A, Bonczek S, et al. The Best Practice Tariff helps improve management of neck of femur fractures: a completed audit loop. Br J Hosp Med (Lond) 2013;74:644-7.

28. Currie CT, Hutchison JD. Audit, guidelines and standards: clinical governance for hip fracture care in Scotland. Disabil Rehabil 2005;27:1099-105.

29. Hughson J, Newman J, Pendleton RC. Hip fracture management for the hospital-based clinician: a review of the evidence and best practices. Hosp Pract (Minneap) 2011;39:52-61.

30. Teo SP, Mador J. Orthogeriatrics service for hip fracture patients in Dunedin hospital: achieving standards of hip fracture care. J Clin Gerontol Geriatr 2012;3:62-7.

31. Shaw CD, Groene O, Botje D, et al. The effect of certification and accreditation on quality management in 4 clinical services in 73 European hospitals. Int J Qual Health Care 2014;26(Suppl 1):100-7.

32. Sunol R, Wagner C, Arah OA, et al. Evidence-based organization and patient safety strategies in European hospitals. Int J Qual Health Care 2014;26(Suppl 1):47-55.

33. Ellanti $P$, Cushen $B$, Galbraith $A$, et al. Improving hip fracture care in Ireland: a preliminary report of the Irish hip fracture database. J Osteoporos 2014;2014:656357.

34. Chang FH, Latham NK, Ni P, et al. Does self-efficacy mediate functional change in older adults participating in an exercise program after hip fracture? A randomized controlled trial. Arch Phys Med Rehabil 2015;96:1014-1020.e1.

35. Resnick B, D'Adamo C, Shardell M, et al. Adherence to an exercise intervention among older women post hip fracture. J Clin Sport Psychol 2008;2:41-56.

36. Jung HY, Meucci M, Unruh MA, et al. Antipsychotic use in nursing home residents admitted with hip fracture. J Am Geriatr Soc 2013;61:101-6.

37. Anand S, Buch K. Post-discharge symptomatic thromboembolic events in hip fracture patients. Ann $R$ Coll Surg Engl 2007:89:517-20.

38. Smith TO, Hameed YA, Cross JL, et al. Enhanced rehabilitation and care models for adults with dementia following hip fracture surgery. Cochrane Database Syst Rev 2015;(6):CD010569.

39. Duncan PW, Velozo CA. State-of-the-Science on postacute rehabilitation: measurement and methodologies for assessing quality and establishing policy for postacute care. Arch Phys Med Rehabil 2007;88:1482-7.

40. Leland NE, Gozalo P, Bynum J, et al. What happens to patients when they fracture their hip during a skilled nursing facility stay? J Am Med Dir Assoc 2015;16:767-74.

41. Pitzul KB, Munce SEP, Perrier L, et al. Quality indicators for hip fracture patients: a scoping review protocol. BMJ Open 2014;4: e006543.

42. Arksey H, O'Malley L. Scoping studies: towards a methodological framework. Int J Soc Res Methodol 2005;8:19-32.

43. Levac D, Colquhoun H, O'Brien KK. Scoping studies: advancing the methodology. Implement Sci 2010;5:69. 
44. Sampson M, McGowan J, Cogo E, et al. An evidence-based practice guideline for the peer review of electronic search strategies. J Clin Epidemiol 2009;62:944-52.

45. Menzies IB, Mendelson DA, Kates SL, et al. The impact of comorbidity on perioperative outcomes of hip fractures in a geriatric fracture model. Geriatr Orthop Surg Rehabil 2012;3:129-34.

46. Day GA, Swanson C, Yelland C, et al. Surgical outcomes of a randomised prospective trial involving patients with a proximal femoral fracture. ANZ J Surg 2001;71(1):11-14. http://onlinelibrary. wiley.com/o/cochrane/clcentral/articles/663/CN-00400663/frame. html http://dx.doi.org/10.1046/j.1440-1622.2001.02019.x

47. Beaupre LA, Jones CA, Saunders LD, et al. Best practices for elderly hip fracture patients. A systematic overview of the evidence. $J$ Gen Intern Med 2005;20:1019-25.

48. Collinge CA, McWilliam-Ross $\mathrm{K}$, Beltran MJ, et al. Measures of clinical outcome before, during, and after implementation of a comprehensive geriatric hip fracture program: is there a learning curve. J Orthop Trauma 2013;27:672-6.

49. Baker K, Brierley S, Mitchell G, et al. Effecting change using careplans: experience from two fractured neck of femur pathways. Aust Health Rev 2012;36:308-12.

50. Matityahu A, Elliott I, Marmor M, et al. Time intervals in the treatment of fractured femurs as indicators of the quality of trauma systems. Bull World Health Organ 2014;92:40-50.

51. Merle V, Moret L, Pidhorz L, et al. Does comparison of performance lead to better care? A pilot observational study in patients admitted for hip fracture in three French public hospitals. Int J Qual Health Care 2009;21:321-9.

52. Hip Fracture Accelerated Surgical TCT Investigators. Accelerated care versus standard care among patients with hip fracture: the HIP ATTACK pilot trial. CMAJ 2014;186:E52-60.

53. Kristensen MT, Henriksen S, et al. Relative and absolute interteste reliability of the timed up and go test to quantify functional mobility in patients with hip fracture. J Am Geriatr Soc 2011;59:565-7.

54. Suhm N, Kaelin R, Studer P, et al. Orthogeriatric care pathway: a prospective survey of impact on length of stay, mortality and institutionalisation. Arch Orthop Trauma Surg 2014:134:1261-9.

55. Al-Rashid M, Parker MJ. Anticoagulation management in hip fracture patients on warfarin. Injury 2005;36:1311-15.

56. Della Rocca GJ, Crist BD. Hip fracture protocols: what have we changed? Orthop Clin North Am 2013;44:163-82.

57. Smektala R, Endres HG, Dasch B, et al. The effect of time-to-surgery on outcome in elderly patients with proximal femoral fractures. BMC Musculoskelet Disord 2008;9:171.

58. Pickles SM, Coventry LL, Glennon DA, et al. 'Making a difference' a clinical pathway for hip fractures and the advance practice role in managing patients with minimal trauma hip fractures. Int J Orthop Trauma Nurs 2014;18:205-13. 209p.

59. Simunovic ND, Devereaux PJ, Sprague S. Effect of early surgery after hip fracture on mortality and complications: systematic review and meta-analysis. CMAJ 2010;182:1609-16.

60. Granger CV, Deutsch A, Graham JE, et al. The Uniform Data System for Medical Rehabilitation fourth in the series of impairment-specific longitudinal reports from the Uniform Data System for medical Rehabilitation (UDSMR) database. Am J Phys Med Rehabil 2011;90:177-89.

61. Simpson P. Clinical outcomes in transition program for older adults with hip fracture. Outcomes Manag 2002;6:86-92.

62. Adunsky A, Lerner-Geva L, Blumstein T, et al. Improved survival of hip fracture patients treated within a comprehensive geriatric hip fracture unit, compared with standard of care treatment. J Am Med Dir Assoc 2011;12:439-44

63. Eisler J, Cornwall R, Strauss E, et al. Outcomes of elderly patients with nondisplaced femoral neck fractures. J Orthop Trauma 2003;17:S31-37.

64. Lai FH-Y, Soo AK-W, Wong SK-M, et al. Admission cognitive performance and functional gain following inpatient rehabilitation in geriatric patients with hip fractures. Hong Kong J Occup Ther 2003;13:25-33.

65. Hershkovitz A, Kalandariov Z, Hermush V, et al. Factors affecting short-term rehabilitation outcomes of disabled elderly patients with proximal hip fracture. Arch Phys Med Rehabil 2007;88:916-21.

66. Zidén L, Kreuter M, Frandin K. Long-term effects of home rehabilitation after hip fracture-1-year follow-up of functioning, balance confidence, and health-related quality of life in elderly people. Disabil Rehabil 2010;32:18-32.

67. Zidén L, Frändin K, Kreuter M. Home rehabilitation after hip fracture a randomized controlled study on balance confidence, physical function and everyday activities [with consumer summary]. Clin Rehabil 2008;22:1019-33.
68. Allen J, Koziak A, Buddingh S, et al. Rehabilitation in patients with dementia following hip fracture: a systematic review. Physiother Can 2012;64:190-201.

69. Shiri-Sharvit O, Arad M, Mizrahi EH, et al. The association between psychotropic medication use and functional outcome of elderly hip-fracture patients undergoing rehabilitation. Arch Phys Med Rehabil 2005;86:1389-93.

70. Cary MP, Baernholdt M, Anderson RA, et al. Performance-based outcomes of inpatient rehabilitation facilities treating hip fracture patients in the United States. Arch Phys Med Rehabil 2015;96:790-8. 799p.

71. Mizrahi EH, Arad M, Fleissig Y, et al. Gender differences in functional outcome of elderly hip fracture patients. Geriatr Gerontol Int 2014;4:845-50.

72. Wang CY, Graham JE, Karmarkar AM, et al. FIM motor scores for classifying community discharge after inpatient rehabilitation for hip fracture. PM R 2014;6:493-7.

73. Lin PC, Chang SY. Functional recovery among elderly people one year after hip fracture surgery. J Nurs Res 2004;12:72-82.

74. Kammerlander C, Roth T, Friedman SM, et al. Ortho-geriatric service-a literature review comparing different models. Osteoporos Int 2010;21(Suppl 4):S637-646.

75. Leigheb F, Vanhaecht K, Sermeus W, et al. The effect of care pathways for hip fractures: a systematic review. Calcif Tissue Int 2012;91:1-14.

76. Crotty M, Whitehead C, Miller M, et al. Patient and caregive outcomes 12 months after home-based therapy for hip fracture: a randomized controlled trial. Arch Phys Med Rehabil 2003:84:1237-9.

77. Beaupre LA, Cinats JG, Senthilselvan A, et al. Does standardized rehabilitation and discharge planning improve functional recovery in elderly patients with hip fracture? Arch Phys Med Rehabil 2005; 86:2231-9.

78. Tha HS, Armstrong D, Broad J, et al. Hip fracture in Auckland: contrasting models of care in two major hospitals. Intern Med $J$ 2009;39:89-94.

79. Beringer TR, Clarke J, Elliott JR, et al. Outcome following proximal femoral fracture in Northern Ireland. Ulster Med J 2006;75:200-6.

80. Turner J, Gemmell LW, Slater A, et al. Seven year follow-up study of patients receiving surgical treatment for fractured neck of femur. Care Critic III 2006;22:112-14.

81. Gregersen M, Borris LC, Damsgaard EM. Blood transfusion and overall quality of life after hip fracture in frail elderly patients-the transfusion requirements in Frail Elderly Randomized Controlled Trial. J Am Med Dir Assoc 2015;9:762-6.

82. Doshi HK, Ramason R, Azellarasi J, et al. Orthogeriatric model for hip fracture patients in Singapore: our early experience and initial outcomes. Arch Orthop Trauma Surg 2014:134:351-7.

83. Haywood KL, Griffin XL, Achten J, et al. Developing a core outcome set for hip fracture trials. Bone Joint $J$ 2014;96-B:1016-23.

84. Bliemel C, Lechler P, Oberkircher L, et al. Effect of preexisting cognitive impairment on in-patient treatment and discharge management among elderly patients with hip fractures. Dement Geriatr Cogn Disord 2015;40:33-43. 11p.

85. Bliemel C, Oberkircher L, Eschbach DA, et al. Impact of Parkinson's disease on the acute care treatment and medium-term functional outcome in geriatric hip fracture patients. Arch Orthop Trauma Surg 2015;11:1519-26.

86. Orive M, Aguirre U, García-Gutiérrez $\mathrm{S}$, et al. Changes in health-related quality of life and activities of daily living after hip fracture because of a fall in elderly patients: a prospective cohort study. Int J Clin Pract 2015;69:491-500. 410p.

87. Hall SE, Williams JA, Criddle RA. A prospective study of falls following hip fracture in community dwelling older adults. Australas J Ageing 2001;20:73-8.

88. Street $\mathrm{P}$, Thompson J, Bailey M. Management of urinary catheters following hip fracture. Australas J Ageing 2013;19:107-8.

89. Liem IS, Kammerlander C, Suhm N, et al. Identifying a standard set of outcome parameters for the evaluation of orthogeriatric co-management for hip fractures. Injury 2013;44:1403-12.

90. Muir SW, Yohannes AM. The impact of cognitive impairment on rehabilitation outcomes in elderly patients admitted with a femoral neck fracture: a systematic review. $J$ Geriatr Phys Ther 2009;32:24-32.

91. Moseley AM, Sherrington C, Lord SR, et al. Mobility training after hip fracture: a randomised controlled trial. Age Ageing 2009;38:74-80.

92. Latham NK, Harris BA, Bean JF, et al. Effect of a home-based exercise program on functional recovery following rehabilitation after hip fracture: a randomized clinical trial. JAMA 2014;311:700-8. 
93. Handoll HH, Parker MJ. Conservative versus operative treatment for hip fractures in adults. Cochrane Database Syst Rev 2008;(3) CD000337.

94. Coleman EA, Kramer AM, Kowalsky JC, et al. A comparison of functional outcomes after hip fracture in group/staff HMOs and fee-for-service systems. Eff Clin Pract 2000;3:229-39.

95. Vidán M, Serra JA, Moreno C, et al. Efficacy of a comprehensive geriatric intervention in older patients hospitalized for hip fracture: a randomized, controlled trial. J Am Geriatr Soc 2005;53:1476-82.

96. Johansen I, Lindbaek M, Stanghelle JK. Structured community-based inpatient rehabilitation of older patients is better than standard primary health care rehabilitation: an open comparative study. Disabil Rehabil 2012;34:2039-46.

97. Binder EF, Brown M, Sinacore DR, et al. Effects of extended outpatient rehabilitation after hip fracture: a randomized controlled trial. JAMA 2004;292:837-46.

98. Chudyk AM, Jutai JW, Petrella RJ. Systematic review of hip fracture rehabilitation practices in the elderly. Arch Phys Med Rehabil 2009;90:246-62.

99. Bryant DM, Sanders DW, Coles CP, et al. Selection of outcome measures for patients with hip fracture. J Orthop Trauma 2009;23:434-41.

100. Cranney AB, Coyle D, Hopman WM, et al. Prospective evaluation of preferences and quality of life in women with hip fractures. $J$ Rheumatol 2005;32:2393-9.

101. Shyu YI, Liang J, Wu CC, et al. An interdisciplinary intervention for older Taiwanese patients after surgery for hip fracture improves health-related quality of life. BMC Musculoskelet Disord 2010;11:225.

102. Shyu YI, Liang J, Tseng MY, et al. Comprehensive and subacute care interventions improve health-related quality of life for older patients after surgery for hip fracture: a randomised controlled trial. Int J Nurs Stud 2013;50:1013-24.
103. Gjertsen JE, Engesaeter LB, Furnes O, et al. The Norwegian Hip Fracture Register: experiences after the first 2 years and 15,576 reported operations. Acta Orthop 2008;79:583-93.

104. Parsons N, Griffin XL, Achten J, et al. Outcome assessment after hip fracture: is EQ-5D the answer? Bone Joint Res 2014;3:69-75

105. Hagsten B, Svensson O, Gardulf A. Health-related quality of life and self-reported ability concerning ADL and IADL after hip fracture: a randomized trial. Acta Orthop Scand 2006;77:114-19.

106. Leland NE, Gozalo P, Bynum J, et al. What happens to patients when they fracture their hip during a skilled nursing facility stay? J Am Med Dir Assoc 2015;9:767-74. http://ovidsp.ovid.com/ ovidweb.cgi?

$T=J S \& P A G E=r e f e r e n c e \& D=e m e d 13 \& N E W S=N \& A N=2015993996$.

107. Giusti A, Barone A, Razzano M, et al. Optimal setting and care organization in the management of older adults with hip fracture. Eur J Phys Rehabil Med 2011;47:281-96.

108. Mont MA, Banerjee A, Jaurequi JJ, et al. What outcome metrics do the various knee rating systems for assessment of outcomes following total knee arthroplasty measure? A systematic review of literature. Surg Technol Int 2015;26:269-74.

109. Ritchie L, Wright-St Clair VA, Keogh J, et al. Community integration after traumatic brain injury: a systematic review of the clinical implications of measurement and service provision for older adults. Arch Phys Med Rehabil 2014;95:163-74.

110. Sleat GK, Ardolino AM, Willett KM. Outcome measures in major trauma care: a review of current international trauma registry practice. J Emerg Med 2011;28:1008-12.

111. Rinere-O'Brien S. Trends in inpatient rehabilitation stroke outcomes before and after advent of the prospective payment system: a systematic review. J Neurol Phys Ther 2010;34:17-23.

112. Grace SL, Poirier P, Norris CM, et al. Pan-Canadian development of cardiac rehabilitation and secondary prevention quality indicators. Can J Cardiol 2014;30:945-8. 